Published as: Energy Policy 104, 382-394

\title{
Global impact of uncertainties in China's gas market
}

\author{
SHI Xunpeng ${ }^{a, b}$, Hari MP*b and Jacqueline Tao ${ }^{b}$
}

\begin{abstract}
a. Australia-China Relations Institute, University of Technology Sydney, 15 Broadway Ultimo, NSW 2007, Australia;

b. Energy Studies Institute, National University of Singapore, 29 Heng Mui Keng Terrace, \#10-01, Bld A, Singapore 119620, Singapore.
\end{abstract}

\begin{abstract}
This paper examines the uncertainties in Chinese gas markets, analyze the reasons and quantify their impact on the world gas market. A literature review found significant variability among the outlooks on China's gas sector. Further assessment found that uncertainties in economic growth, structural change in markets, environmental regulations, price and institutional changes contribute to the uncertainties. The analysis of China's demand and supply uncertainties with a world gas-trading model found significant changes in global production, trade patterns and spot prices, with pipeline exporters being most affected. China's domestic production and pipeline imports from Central Asia are the major buffers that can offset much of the uncertainties. The study finds an asymmetric phenomenon. Pipeline imports are responding to China's uncertainties in both low and high demand scenarios while LNG imports are only responding to high demand scenario. The major reasons are higher TOP levels and the current practice of import only up to the minimum TOP levels for LNG, as well as a lack of liberalized gas markets. The study shows that it is necessary to create LNG markets that can respond to market dynamics, through either a reduction of TOP levels or change of pricing mechanisms to hub indexation.
\end{abstract}

Key Words: Natural Gas; Gas market; China; Uncertainty;

JEL: Q41, C35 


\section{Introduction}

China's gas market plays an important role in the global gas market and its importance is expected to increase over time. In the 2015 World Energy Outlook 2015 (IEA, 2015b), the International Energy Agency (IEA) forecasted that China has the highest growth prospects in natural gas demand from 2013 to 2040 globally. With current consumption of about 200 billion cubic meters (bcm), China is the world's third-largest gas consumer (BP, 2016) and its gas consumption is projected to grow to about 600 bcm by 2040 (IEA, 2015b). In total, Chinese gas demand as a share of world gas production is expected to increase from 5\% in 2015 to $11 \%$ by 2035 (IEA, 2015b). This increased demand is met partially by increased domestic production, with the bulk supplemented by imports from both pipelines and LNG. IEA estimates that Chinese import dependence is set to increase from 30\% of demand in 2015 to $40 \%$ with total imports up to 200bcm by 2035 (IEA, 2015a).

Despite high growth in the early 2000s, the trend of increasing Chinese demand for natural gas seems to be dying down, with the growth rate in natural gas consumption reaching historical lows in recent years (Shi and Variam, 2015). While slow economic growth is an obvious reason, there are many other initiatives in China that will cast great uncertainties on China's gas sector and the global gas market. The uncertainties could be due to technical reasons (such as reduction of shale gas production costs), regulatory reasons (such as limitation of coal usage for local pollution reduction and $\mathrm{CO}_{2}$ abatement), institutional reasons (such as pricing reforms and market liberalization), or a combination of some or all of them.

This confluence of increased significance, import dependence and the Chinese gas market as wildcard when it comes to supply and demand creates much uncertainty for global gas players 
(Ratner et al., 2016). In particular, the uncertainties have a great impact on LNG trade as it is expected that the glut in the world gas markets, in particular the LNG markets, will be unlikely to disappear before 2020 due to factors such as contract arrangements, high capital intensity, and long lead times for project development (Shi, 2016b).

While there are studies in the literature that examined the various outlooks of China's gas supply and demand (Ratner et al., 2016; Shaikh and Ji, 2016; Sun Hui Shan Lei Wang, 2013; Wang et al., 2013a; Wang et al., 2016; Wang and Lin, 2012, 2014; Zhang, 2014; Zhu et al., 2014); to the best of our knowledge, there is no study quantifying the impact of China's gas market uncertainties on regional and global gas markets. The regional and global impacts of China's gas market sector development remain a relatively new issue for most energy researchers (Shi and Variam, 2015). Although many observers predict a slump in gas prices once the global market faces diminished Chinese demand (Butler, 2015), such impacts are not quantified.

The current paper not only reviews and analyses the factors contributing to demand and supply uncertainties in China, but also estimate the impact of uncertainties on the world gas production, gas prices, pipeline and LNG trade. Questions to be answered in this paper include: (1) what are the magnitude of uncertainties in China's gas market? (2) what factors have led to these significant uncertainties? (3) what would the uncertainties mean for the world gas market?

This paper aims to contribute to the understanding of the comprehensive global impacts from China's gas market uncertainties, which are expected to provide reference for the international gas industry, in terms of project development and contract negotiation. It should also be able to offer implications on the ongoing changes in price indexation and trading hub initiatives in East 
Asia, which is closely related to market conditions as demonstrated by a recent study (Shi and Variam, 2016).

The paper proceeds as follows. Section 2 explains the methodology and the model. Section 3 reviews and analyses both supply and demand uncertainties in the literature. Based on the

analysis and reviews, a group of policy scenarios are proposed in Section 4, which also presents the modeling results and discussions. Section 5 discusses the global and regional impact of the results. The last section concludes the paper with policy implications.

\section{Model and Methodology}

This paper is presented as two main interrelated parts. The first part is a qualitative study where we review the relevant factors underpinning the uncertainties in China's gas supply and demand. Based on these reviews, a group of scenarios that represents different uncertainties are proposed. The second portion consists of a quantitative examination of how global gas markets evolve under different scenarios of Chinese demand and supply change using a global gas market and trade model.

The global impact of China gas market uncertainties is simulated by the Nexant World Gas Model (WGM) (Nexant, 2016). The WGM model, which covers every country that produces or consumes gas, is formulated as a linear programing model with minimization of global gas procurement costs (including production costs and transport costs) as the objective. The model is a mirror of gas sector in reality without dynamic intervention of government. Strategic government intervention can be modelled as infrastructure start dates, and change in price indexation (wherever applicable), taxes and production subsidies. The model includes all known 
sales contracts including source and destination, Annual Contract Quantity (ACQ), start and end dates, price formula, and active and planned infrastructure. The model minimizes cost of production and transportation to meet projected demand, subject to infrastructure constraints. Flows within nodes are constrained according to the available infrastructure and within the bounds of long term contracts where appropriate. Countries are modelled as nodes in WGM. The model captures flows at the node level by pipeline and LNG and contracted and un-contracted flows are separately identified. While most countries are modelled as single node, larger countries are further divided into several nodes. Nodes are balanced on a quarterly basis to account for seasonal demand variations, supply swing, flexibility of delivery infrastructure and storage capacities. The model is optimized at node level but the results are aggregated to country and even regional blocks to simplify the presentation.

Detailed explanation of the model, the regional classification, key assumptions and inputs, and the discussion of results from reference scenario can be found in Shi and Variam (2016) .

\section{Chinese Gas Market Uncertainties}

\subsection{Demand uncertainty}

Generally, opinions seem to align around a largely optimistic view on the natural demand in China. While demand growth is relatively assured, the rate of demand growth is uncertain. The uncertainty on the magnitude of future growth is clearly illustrated in the disparities between official, academic as well as private sector forecasts. According to a review of existing literature on forecasts of Chinese demand from governmental, industry and academic sources, the range of demand forecast for 2020 lies between $270 \mathrm{bcm}$ to $500 \mathrm{bcm}$ and $400 \mathrm{bcm}$ to $700 \mathrm{bcm}$ for 2030 
(Figure 1; Compiled from (CCR, 2013; Chen, 2013; CNPC, 2016a; Diao et al., 2014; Gastreich et al., 2013; Guo and Zhou, 2015; IEA, 2015a, 2016; IEEJ, 2015; NDRC, 2014a; Por, 2013; Rogers and Stern, 2014; Shaikh and Ji, 2016; Shi, 2016a; Trevor and Bao, 2013; Zeng and Li, 2016; Zhang, 2014; Zhang and Yang, 2015). The magnitude of the degree of uncertainty is best illustrated by the fact that even the differential between the highest and lowest forecasted demand is more than China' gas consumption in 2015 (196 bcm, as reported by (CNPC, 2016b) ) and close to the size of the global traded LNG in 2015 (245 Mt, about 300 bcm) (GIIGNL, 2016).

\section{[INSERT FIGURE 1 HERE]}

Further evidence of uncertainty can be observed from frequent revisions of not only private sector forecasts, but also official state goals and targets. In November 2014, the State Council (2014b) released the “Energy Development Strategy Action Plan (2014-2020)” which forecasted that natural gas will account for more than $10 \%$ of the total primary energy consumption of 4.8 Gt coal equivalent by 2020, equivalent to 360 bcm annual consumption (State Council, 2014b). This represented a downward revision from an earlier more ambitious official estimate of 400 to 420 bcm per annum by 2020 (Rogers, 2015). The 2014 figures were downgraded again in 2015 to about 295 bcm per annum, in alignment with the November 2014 IEA World Energy Outlook (WEO) New Policies Scenario (Rogers, 2015). Such almost annual revisions of natural gas consumption estimates are reflective of the current state of uncertainty in the Chinese gas markets.

\subsection{Supply uncertainty}

On the supply side, outlooks in the literature are also diversified. The forecasted Chinese natural gas production (including both conventional and unconventional gas) in 2020 ranges from 150 
bcm to 270 bcm (Figure 2; Complied from (BP, 2015; CCR, 2013; CEFC, 2013; Diao et al., 2014; IEA, 2015a, 2016; IEEJ, 2015; Li et al., 2016; Rogers and Stern, 2014; State Council, 2014b; Trevor and Bao, 2013; Wang et al., 2013b; Zhang, 2014).

[INSERT FIGURE 2 HERE]

Similar to the case of gas demand, there are constant revisions of official state targets and forecasts. In the Five-Year Shale Gas Development Plan, released by the Chinese government in March 2012, it is targeted that an annual domestic shale gas production will reach $6.5 \mathrm{bcm}$ in 2015, which will further increase to 60-100 bcm by 2020 (Andrews-Speed et al., 2015). In November 2014, the State Council (2014b) released the “Energy Development Strategy Action Plan (2014-2020)", which revised the target numbers for shale gas production downwards to 30 $\mathrm{bcm}$ in the face of a variety of development challenges.

An objective review of the situation is further complicated by the optimist view private sector players hold on shale development in China. Despite initial setbacks, the commercialization of Sinopec's FuLing block and CNPC's three shale blocks seem to raise trust in the ability to capitalize on domestic shale resources (Chen, 2014).

\subsection{Factors that contribute to uncertainty}

The factors that contribute to both demand and supply uncertainty include uncertain total future energy demand, which may be affected by factors such as rate of economic growth, population growth rate and rate of urbanization, among others; and uncertainty in energy mix, in particular, the battle between coal and natural gas, which could be affected by environmental regulations, international oil and gas prices, and market liberalization. 


\subsubsection{Economic slowdown and structural changes}

In recent years, China is facing a slowdown in economic growth as a result of the "new normal" economic model, where it is expected that structural changes towards a technological, innovation and service centric growth is overshadowing the previous secondary and manufacturing sector as the vehicle of growth. Such changes are expected to reduce the total energy demand, and therefore affect future gas demand. The first degree of uncertainty associated with these changes is that the magnitude of the slowdown and structural changes remains a point of controversy, which casts doubt on future forecasts of natural gas demand.

A second layer of uncertainty is added since the relationship between these macroeconomic changes and the domestic gas demand is also not clear. While some observers note that the slowdown of economic growth and the shift towards less energy-intensive sector of growth have contributed to the reduction in total final energy demand, and therefore natural gas demand, (Green and Stern, 2015); others argue that, given the low contribution of gas in the energy mix, uncertainties underpinning the overall energy mix is unlikely to be a significant factor affecting natural gas demand (IEA, 2015a).

\subsubsection{Environmental regulations}

Another cause of uncertainty for China's future gas outlook will be the country's forthcoming climate policy and the corresponding environment regulations. In recent years, environmental concerns are replacing economic growth targets during policymaking discussions. Furthermore, China's high profile policy directives to reduce both local (ambient) pollution and global (carbon emissions) pollution have illustrated the political determination in tackling such issues. Environmental regulations may have a positive impact on future natural gas demand as may increase the attractiveness of natural gas vis-à-vis other fossil fuel based energy sources. 
However, under similar logic, stricter environmental regulations may favor cleaner renewable energy resources over gas. Moreover, given the strain gas extraction process has on the environment, stringent environmental regulations may deter domestic gas production volumes.

In the power generation sector, the policy direction to move away from coal-fired power plants so as to combat environmental pollution is clear. In a series of policy documents, starting from the Air Pollution Prevention and Control Action Plan issued by the State Council in $2013^{1}$ to the 12th and 13th Five Year Plan, the Chinese government have shown a growing commitment to replace coal with cleaner and more efficient generation source to improve ambient air quality (by reducing PM 2.5 and smog). State directives to reduce the share of coal in primary energy supply from 70\% in 2012 to 65\% in 2017 were issued. Aggressive state policies have been also implemented in various sectors, with key target focus in areas such as reducing the demand for coal, setting up de-nitrification facilities, shifting away from obsolete industry capacity as well as promoting clean energy consumption (Chen, 2014). Natural gas being a relatively clean fossil fuel, offer an appropriate alternative to fill the gap, thus potentially affecting future gas demand.

In more developed regions, such as the Jing-Jin-Ji (Beijing-Tianjin-Hebei), Yangtze River Delta and Peer River Delta, a mix of scaling down coal fired power plants, restrictions on new coal fired generation capacity, phasing out of small coal boilers and speeding up of coal-to-gas conversion programs are seen (Chen, 2014). In Jing-Jin-Ji and Shandong, the target to reduce coal demand by 85 million tonnes by 2017 is equivalent to adding an approximate $50 \mathrm{bcm}$ to the country's gas demand. When coupled with the actions of other provinces in containing and reducing coal consumption, the aggregated effect on additional gas demand is expected to be significant.

\footnotetext{
${ }^{1}$ Available at: http://www.gov.cn/zwgk/2013-09/12/content_2486773.htm
} 
However, natural gas is not the only resource which can fill the energy deficit. Renewable energy projects remain a strong contender to fill the potential energy deficit left by coal. The competition between energy sources is best illustrated by the Chinese target of increasing the share of non-fossil fuels and gas in its energy mix to 20\% each by 2030 to meet its target to peak carbon emissions by 2030 and reduce its carbon intensity by a minimum of $60 \%$ by 2030 , from a base year of 2005.

Such explicit policy directions will serve to prop up demand, though the extent of influence is unknown. In fact, the introduction of a national carbon market in 2017 may place renewables at an advantage over gas. Furthermore, the level of restriction on coal-fired power plants is unclear, particularly since the coal industry remains a key sector providing rural employment for the nation (Shi, 2011).

In the heating sector, the fuel switch from coal to gas in heating presents much potential in China. As such, various local and provincial governments are seen to be introducing support systems to promote such a switch. The Beijing provincial government have introduced an up to 50\% subsidy on project costs for replacing a coal boiler with a gas-based one, dependent on the size of the boiler, while Hebei is set to shut down any coal boilers smaller than 10 steam tonne (IEA, 2015a).

\subsubsection{Uncertainty of shale gas development}

Uncertainty surrounding shale gas production contributes to a degree of variation in domestic gas production estimates in China. The inconsistent shale gas outlook is more or less driven by three factors: reserve, production cost and environmental regulation. While the first uncertainty will 
affect the total amount of shale gas supply, the later uncertainty, which mainly depends on technology progress, will affect the timeline that the shale gas will come to the market. Environmental regulation, on the other hand, determines if the shale resources will be exploited. According to EIA (2015), as of 2013, China’s unproved technically recoverable shale gas reserves was $31.6 \mathrm{tcm}$, more than eight times of its total proven gas reserve (3800 bcm or $3.8 \mathrm{tcm}$ ) in 2015 (BP, 2016). In a recent paper, Wang et al. (2016) highlight that Technically Recoverable Resources, which are more useful for production forecast, have a range between 4 tcm to 45 tcm. Wang et al. (2016) further highlight that even the most credible estimates from the U.S. Energy Information Administration/Advanced Resources International Inc (EIA/ARI) and the Ministry of Land Resources (MLR) in China, are mostly preliminary, and are contested by many scholars. With such large variances in resource estimates, some optimists even suggest the potential of gas self-sufficiency for China (Ryan, 2012).

While some argue that discrepancies with regards to technical reserves are not uncommon, a significant portion of variability actually derives from external challenges such as poorly suited and complex geology and water shortages, institutional challenges (acreage ownership issues and lack of third party access to infrastructure), and cost issues (high cost of wells) (Chen, 2014).

The ability to tap its shale resources is dependent on the production cost, which will determine project profitability and guide development decisions. The current higher costs of shale gas relative to conventional gas deter the large scale development of shale gas. (Ren et al., 2015) citing data from Bloomberg New Energy Finance, observes that the wellhead cost of shale gas in China in 2015 to be around US\$11.20 \$/MMBtu, compared to the cost for the exploitation of dry gas in US (3.40\$/MMBtu). Further evidence can be obtained from Tian et al. (2014), which 
brought into focus the financial losses faced by Sinopec and CNPC who were able to get US\$10.87/Mcf (inclusive of an estimated wellhead gas price of about $\$ 9.06 /$ Mcf and the subsidy for shale gas at $\$ 1.81 / \mathrm{Mcf}$ ) after an initial investment of US $\$ 0.37$ billion and $\$ 0.64$ billion in investment for 2.58 Bcf and 2.47 Bcf of gas development, respectively. While improved technology and experience are likely to push down costs, at what speed remains to be a question.

Governmental policies to subsidize production costs may serve to reduce costs, but such policy support faces much uncertainty into the future. First implemented in 2012, China has a regressive subsidy policy to shale gas developers. In 2012, the government announced a fiscal subsidy policy of is $0.4 \mathrm{yuan} / \mathrm{m}^{3}$ for shale gas to be effective from 2013 to 2015 (Ministry of Finance, 2012).The subsidy allocated from 2016 to 2018 is 0.3 yuan $/ \mathrm{m}^{3}$, with a further reduction to 0.2 yuan/ $\mathrm{m}^{3}$ from 2019 to 2020 (Ministry of Finance, 2015). Top domestic energy companies have been calling for an extension of the subsidy to 2030 (Ministry of Finance, 2016), which under current policy environment, is not an exaggerated option, but the outcome remains uncertain.

Environmental regulations may also have an impact on shale gas production. Current literature seem to agree than the potential environment risks of shale gas production in China are greater than that in the United States (Krupnick et al., 2014). One of the most pressing issue at hand is the water-related risks. Citing Guo et al. (2014) and Yang et al, (2014), (Wang et al., 2014; Yang et al., 2013) states that each of the shale wells in China consume an estimated of $10,000 \mathrm{~m}^{3}$ to $24,000 \mathrm{~m}^{3}$ of water daily, which strains the delicate balance between water consumption for shale development and other socio-economic goals, especially in the arid areas in the Tarim Basin. Such constraints were further highlighted by a report by World Resources Institutes (WRI), in which they estimate that more than $60 \%$ of China's shale resources face high water stress, which creates business risks for companies operating in these areas (Reig et al., 2014). Unfavorable 
conditions are further exacerbated by the high population density in these areas (Reig et al., 2014). Pollution of both surface and ground water was also highlighted by (Wang et al., 2014) as a potential cause of concern. Citing fieldwork in the Sichuan Basin in June 2013, it was revealed that due to high monitoring costs, some shale gas operators tend to overlook water pollution regulations. Furthermore, due to high penalties for ground water pollution, some businesses even choose to pollute surface water (Wang et al., 2014). Should regulation targeting such environment constraints tighten, shale gas production may be adversely affected.

\subsubsection{Price uncertainty and institutional changes}

A further source of uncertainty will be the price and regulatory uncertainty surrounding the Chinese gas market. Natural gas is losing out in both absolute and relative economic competitiveness in the previous era of stable oil and low coal prices (IEA, 2015a). A combination of reliance on imported gas, high import costs and regulated end-user prices have negatively affected profitability of the natural gas sector and may have strong impact on the future of the industry, and the overall demand. China is reliant on import for over $60 \%$ of its natural gas consumption(IEA, 2015a). With an average LNG import price of USD 11/MMBtu in 2014, the highest price recorded at USD 20/MMBtu, and pipeline imports coming at a cost of USD 9.5/MMBtu, the corresponding increase in end-user prices have a limited effect in bridging profitability gaps (IEA, 2015a). This loss of competitiveness may have been the main contributor to the slowdown of natural gas demand growth from the average $14 \%$ per annum(p.a.) in the period 2009-2013, to the 8\% to 9\% p.a. in 2014 (Blume, 2015; IEA, 2015a).

While the current low import prices could have spurred demand response (Shi, 2016b), it has not been the case in China because the regulated domestic pricing have prevented the final consumers from benefiting from the low import prices. Even more so, gas demand could be 
discouraged due to cheaper alternatives to gas, such as liquefied petroleum gas (LPG) on the eastern coast markets.

In this case, the ongoing efforts to liberalize domestic gas prices and markets create another layer of uncertainty, in addition to the uncertainty to the global gas prices. In recent years, favorable policies could be seen from the market liberalization process and the interest in reforming domestic natural gas pricing. Historically, the Chinese government controlled the price of natural gas using a cost-plus approach which was replaced by netback pricing mechanism (Shi and Variam, 2015). However, there are still a few distortions: the city-gate prices are still set by NDRC without transparent information on procedure and frequency and cannot reflect the real time market fundamentals. The consequence is particularly serious in the current period of sharp fluctuating prices. Secondly, residential gas prices are still distorted by the regulated tiered price mechanism.

Under the current policy environment, there seems to be various new policy reforms in the pipelines, such as liberalization of retail prices, which may affect consumption patterns (Shi and Variam, 2015). A liberalization of the wholesale and retail prices will affect the relative prices of gas to other fuels and thus affect both gas demand and supply through partly altering the share of natural gas in the total energy demand. In addition, the likely subsequent intention towards the establishment of gas trading hubs will shift the pricing reform toward spot indexation gas pricing. This process will not only change the domestic gas sector, but also influence gas imports through indexing import to benchmark hub prices. The impact of a hub indexation will not only affect the Chinese gas market, but also the regional and global gas markets due to the significant size of China's gas market at the present and in the future (Shi and Variam, 2015, 2016). 
In addition to the pricing mechanism, many other potential institutional changes will also be expected to affect the natural gas sector.

Firstly, liberalization in the upstream that is envisioned by the top decision makers (The 18th Central Committee of CPC, 2013) may incentivize shale gas and other unconventional gas development through non-economic measures, such as enhanced access to resources and land, which are traditionally dominated by the NOCs (Andrews-Speed et al., 2015). The largely monopolistic control over upstream exploration rights is also a source of concern for the scale of shale gas development. Currently, allocation of gas block possession is carried out by the State Council (Zhang et al., 2015). Although it is theoretically possible for individuals and private companies to obtain a license for upstream shale gas exploration rights, the market remains dominated by large state-owned enterprises (SOEs). (Ren et al., 2015) estimates the state-owned enterprises, including CNPC (China National Petroleum Corporation), China Petrochemical Corporation (Sinopec), and Shaanxi Yanchang Petroleum Co., Ltd, owned or controlled about 80\% of shale gas resources in 2013. Learning from the US shale gas experience, (Ren et al., 2015)observed that the involvement of private sector companies could expedite land transfer or leasing.

Secondly, mandatory implementation of third party access to LNG receiving terminals and pipelines can boost competition and link domestic gas market the regional and world LNG prices. On top of this, lower economic growth and regulated high gas prices have led to slowing gas demand growth in China and concerns that China will struggle to absorb the increase in contracted LNG volumes (Dodge, 2016). However, this will be changed sooner or later once the third party access policy is functioning. 
Lastly, the development of LNG terminals owned by the private sector will also further integrate the Chinese domestic markets to the world markets. Due to regulations, the private gas players did not have the privilege to sign long term LNG contracts and thus avoided the locked in of high costs and inflexible LNG supplies. With the decentralization of LNG terminal approval (State Council, 2014a), the private gas importers are now more likely to have their own terminals which will bring gas whenever it is profitable (Platts, 2015). Since the domestic prices for imported LNG was allowed to be market determined in September 2014 (NDRC, 2014b), a further proliferation of privately owned LNG terminals will change the domestic prices and have an impact on both gas supply and demand.

\section{Modeling and results}

As the discussion above have illustrated there are various contributing factors of uncertainty underpinning the Chinese market. Complexities arise when the various factors interact with each other, further complicating analysis in the subject matter. An analysis whereby the one parameter is changed whereas others remain ceteris paribus can be largely unrealistic, given the interdependency of the factors described above. Therefore, to better present a holistic

representation of potential pathways for the Chinese natural gas market going into the future, we have decided to base our analysis on broad demand and supply shocks in the Chinese market. While recognizing the potential inadequacy of such assumptions, we deem this approach to be in alignment with the purpose of this paper, which aims to understand the impacts of changes in Chinese demand and supply shocks on the global market. 


\subsection{Scenario setting}

As such, we have formulated three policy scenarios, covering both demand and supply shocks, shale gas development, in addition to the reference scenario (Table 1).

In our reference scenario (REF), we adopt the domestic gas demand projections from the New Policy Scenario (NPS) in the IEA World Energy Outlook (WEO) 2016 (IEA, 2015b). The shale gas production was constructed broadly based on the WEO 2015 NPS estimates for Chinese unconventional gas, with linear extrapolation methods being used to estimate figures for intermediate years between 2020, 2030 and 2035. The use of 2015 data was due to data availability restrictions in the 2016 report. Under the reference scenario, we also assume that the Eastern pipeline (Power of Siberia) from Russia will start operations in 2020, with an initial annual export capacity of $10 \mathrm{bcm}$ in the first two years, which will be ramped up to $28 \mathrm{bcm}$ in 2022, and to $38 \mathrm{bcm}$ per annum in 2024. The Western pipeline (Altai route) will also be operational in 2030 with a capacity of $30 \mathrm{bcm}$ per annum.

To address demand uncertainty, a high demand and a low demand scenario are constructed. Both low and high demand forecasts are in line with data obtained from CNPC(CNPC, 2016a). Given that CNPC data only provides forecasts up to 2030, forecasts to 2035 are estimated as a linear expolation of the average growth of the previous 10 years.

In modelling possible supply uncertainties, we have decided to focus on the variability in shale gas production. Considering that the IEA baseline shale gas production estimate is lower than the Chinese government target, and the uncertainties of a lower shale gas production will be minor, we do not simulate any low shale gas production scenario. For the high domestic shale gas production scenario, we performed a linear extrapolation on high Chinese unconventional gas 
production estimates available in the IEA World Energy Outlook 2015 (IEA, 2015b). Table 1 below summarizes our assumptions.

[INSERT TABLE 1HERE]

The incremental demand from both scenarios is summarized in Figure 3. The overall increase in demand from China is +35 bcm/year (overall +9\% over base case) on average for "High Demand" scenario and -66 bcm/year (overall-17\% over base case) in Chinese demand for the period 20152035 in "Low Demand” scenario. The impact of the positive and negative demand shock from the perspective of overall global demand is at $+0.8 \%$ and $-1.5 \%$ respectively.

[INSERT FIGURE 3HERE]

\subsection{Reference scenario}

In the reference scenario, global gas production and consumption is projected to increase at a compound annual growth rate (CAGR) of 1.6\% from 3550 bcm in 2015 to 4860 bcm in 2035 (Figure 4). Incremental global gas supply comes from North America, Former Soviet Union (Russia and Caspian countries), Middle East and Australia (Figure 4). Most of the consumption increase is observed in China, Middle East and India. The natural gas consumption from China and India are projected to grow at a CAGR of 5.1\% and 5.5\% respectively during the period 2015-2035.

\section{[INSERT FIGURE 4 HERE]}

Global LNG exports are expected to increase at a CAGR of 3.6\% from 330 bcm in 2015 to 670 bcm in 2035 (Figure 5). Key LNG trade routes are Australia to Japan, Korea and China (East Asia), South East Asia to East Asia, Middle East to East Asia, Middle East to India, North 
America to North East Asia and North America to Europe. Pipeline gas flows increase at a moderate CAGR of 1.9\% from 2020 bcm in 2015 to 2920 bcm in 2035 (Figure 5). Major pipeline export trade routes are Russia to Europe, Central Asia to China, Russia to China and North Africa to Europe.

[INSERT FIGURE 1 HERE]

Natural gas spot prices are expected to see a decline from 2015 till around 2020, in line with decline in oil prices, before rising steadily to original price levels at around \$10/MMBtu in Asia and Europe. Asian prices are generally higher than European and North American gas prices (Figure 6).

[INSERT FIGURE 6 HERE]

\subsection{High Demand and Low Demand scenarios}

Under both upward and downward demand shock, China is able to adjust its domestic production to meet most of its changing needs, and stabilize the domestic natural gas market. Domestic production in China increases by an average $+15 \mathrm{bcm} /$ year (55\% of domestic consumption increase) in high demand scenario, while domestic production decreases by an average 40 bcm/year (64\% of domestic consumption decrease) on low demand scenario. The high cost production fields (at the margin) and limited unconventional gas production at market prices make production 'upward sticky' in satisfying the shock in demand.

Besides altering domestic production, Chinese gas demand changes also have large impacts on the natural gas market in Central Asia whose production changes to cater to the changing 
demand from China in both scenarios (Figure 7.a). This is due to i) Central Asian (Caspian) gas supply contracts are relatively flexible in Take-Or-Pay (TOP) provisions when compared to LNG contracts; and ii) Pipe imported gas from Central Asia is cost competitive with LNG and can bridge the supply gaps in high demand scenario. North American production is also seen to be increasing after 2030 when new supply to North East Asia starts. In the low demand scenario, the Southeast Asian production replace the North American production to be the third responding source. However, the magnitude of change in Southeast Asian production is much smaller than the two leading one: China and Caspian production. For the rest regions, the change of production is minor (Figure 7.b).

[INSERT FIGURE 7.a and 7.b HERE]

Increased Chinese demand not satisfied by domestic production increase is met by LNG imports (61\%) and by pipeline imports (39\%) in the high demand scenario. LNG imports to China increase by $152 \mathrm{bcm}$. More than 64\% of the increased exports to China come from Southeast Asia (Malaysia and Indonesia) and Australia. LNG exports from Middle East and Africa bridge the gap with remaining 36\% share (Figure 8.a). Under high demand scenario, import pipeline capacity utilization rises close to $100 \%$ in China, and is a limiting factor in further growth in pipe exports. Pipeline imports increase by $97 \mathrm{bcm}$ over the forecast period, with $90 \%$ of the increased imports come from Caspian and Russia (Figure 8.b). Russian exports start only after 2020 in line with the start of pipeline (Eastern route), which displaces some of the incremental exports from Caspian countries.

[INSERT FIGURE 8.a and FIGURE 8.b HERE]

Decreased Chinese demand not satisfied through decrease in domestic production, is almost all 
met through decreased pipeline imports (97\%) from Central Asia and Russia (Fig 9.b). In contrast, LNG imports to China do not change very much. (Figure 9.a)

Under both high and low demand scenarios, the demand increase/shortfall are met by either altering domestic production or through adjusting pipeline imports. Only in the high demand scenario whereby pipeline capacity are nearly maximized are spot LNG imports employed. Thus pipeline exports from Central Asia and Russia have the potential to act as the swing supply source in demand shock scenario in China. This is also due to LNG supply already at TOP level and any reductions beyond the minimum level are not taken due to higher cost of penalty.

[INSERT FIGURE 9.a and FIGURE 9.b HERE]

Spot prices in China increase on an average by US\$ 1.45/ MMBtu from 2020 to 2035 in the high demand scenario and spot prices decrease on an average by US\$ 2.1/ MMBtu from over the same period in the low demand scenario (Figure 10.a). China's high demand will have more impact on South East Asia and Australia prices, the largest source of LNG to China, than the low demand scenarios due to LNG's reduced responsiveness to demand shocks (Figure 10.b). Spot prices are also affected in Russia, the largest source of pipeline imports. The impact on prices in other regions is not significant.

[INSERT FIGURE 10.a and FIGURE 10.b HERE]

\subsection{High shale production scenarios}

Under a high domestic shale gas production in China scenario, the LNG imports to China remain unchanged. Changes of production are observed in China and Caspian (Figure 11).

[INSERT FIGURE 11 HERE] 
High shale production has limited impact on Chinas LNG imports due to the relative contract inflexibility of LNG imports (Figure 12.a). The decrease in Caspian production is on account of the high domestic shale gas production from China directly displacing the pipeline imports from Caspian and Russia (Figure 12.b).

[INSERT FIGURE 12.a and FIGURE 12.b HERE]

A high shale production will marginally depress major regional spot prices, with the exception of Henry Hub. The largest price drop is observed in China spot prices, followed by Russian spot prices (Figure 13). The Chinese prices declines due to i) The production of more shale gas at current production cost increases supply options; and ii) increased supply makes the Chinese domestic market less tight leading to lower spot prices.

[INSERT FIGURE 13 HERE]

\section{Discussion}

The simulations found that China's domestic production and imports from Central Asia and Russia are the major buffers that can offset much of the uncertainties in demand and supply. Chinese gas demand changes have large impacts on the natural gas market in Central Asia whose production changes to cater to the changing demand from China in both the demand scenarios.

There are increased pipeline exports in case of high demand and decreased exports in the low demand scenario. Thus, pipeline exports from Central Asia and Russia respond to the demand uncertainties in China. In contrast, LNG exports change only during the high demand scenario. The simulations demonstrate that China' uncertainties will have significant impact on domestic prices and only marginal impact on natural gas prices in major gas markets. The largest impact 
on spot prices are observed in regions where exports change the most in response to Chinese demand uncertainties.

The impact of China's uncertainties on global LNG market is asymmetric between high and low demand scenarios. In the high demand case, the impact on LNG market is magnified as the additional volume of LNG can be sourced from a diverse pool of suppliers and there is little capacity limit given China’s current underutilized regasification capacity. In contrast, the fixed pipeline capacity limit the upward flexibility of pipeline exports in responding to high demand. In the high demand scenario, Southeast Asian LNG imports to China will increase to bridge the supply gap. However, in the low demand case, the impact on global LNG markets is very much reduced, with most of the uncertainties borne by changes in Chinese pipeline imports.

We suspect that the asymmetries in market behavior between the LNG and pipeline gas and between high demand and low demand scenarios are due to the more rigorous contract terms of LNG imports, as compared to pipeline imports. The TOP level in LNG contracts is typically set at an average of $85 \%$ while the TOP for pipeline contracts to China is at an average of $70 \%$. Due to the current and projected low oil prices, China's long term contracted LNG prices are not cost competitive and thus the Chinese importers only takes the minimum TOP levels and there is no room for further reduction in LNG imports in the lower demand scenario. As a result, Chinas has to shut-down its most expensive domestic production and relatively flexible pipeline imports from the Caspian exporters when faced with downward uncertainties.

To examine the impact of TOP provisions, we remove TOP restriction in all Chinese LNG import contracts from 2015 under the low demand scenario. Results support our hypotheses that the lack of response from the LNG market in the low demand scenario is due to TOP restrictions 
that prevent reductions in LNG supply. When we remove TOP obligations from the Chinese LNG imports, China's LNG imports from all regions will be reduced throughout the study period (Figure 14).

[INSERT FIGURE 14 HERE]

Pipeline imports to China also experience significant changes. Central Asian and Russian imports are impacted if LNG TOP obligation is removed. However, the onset of reductions is delayed due to effect of reduced LNG flows till 2025. Southeast pipeline (from Myanmar), however, is robust to the LNG TOP change (Figure 15).

\section{[INSERT FIGURE 15 HERE]}

Moreover, China's production also marginally increases. This suggest that China's domestic production is cost competitive to LNG imports but its growth potential is inhibited by the minimum TOP clauses in the low demand scenario. In other words, LNG exporters from other regions, except Southeast Asia, are protected by the TOP provisions in LNG contracts. Unless there is a way to renegotiate and reduce the TOP level for those LNG contracts, China's gas market uncertainties will continue to put pressure on pipeline gas imports. The role of LNG as the flexible source of supply in uncertain demand is diminished in a rigid contractual environment with tight TOP and DES clauses. Lower contractual restrictions in a no TOP scenario are beneficial for the world. Total procurement cost of the world declines (Table 2) in the China Low Demand - No TOP scenario when compared to Low Demand with TOP.

\section{[INSERT TABLE 2 HERE]}

The stability of LNG due to TOP and other commercial arrangements may cause distort market behaviors, and is unsustainable. An ongoing initiative in the East Asian region in creating spot LNG markets through liberalization of the LNG contracts may lead to lower TOP levels in the 
current and future contracts (Shi and Variam, 2016). In this dynamic process, the transition to moving away from oil indexation through price review and arbitration may have to be initiated in China.

\section{Conclusion and policy implications}

China's gas demand is expected to account for a growing share of the world total demand; hence its uncertainties will likely have significant impacts on regional and global trade of LNG, pipeline gas and their prices. This study quantifies the impact of Chinese uncertainties on global gas markets. Specifically, our results showed changes in Chinese demand have an asymmetric impact on LNG and Pipeline: pipeline exports are responding to both the upside and downsides of China’s demand uncertainties while LNG exports only are only responding to high demand. The major reasons are higher TOP levels in LNG contracts than pipeline contracts and the current practice of import only up to the minimum TOP levels, as well as a lack of liberalized gas markets.

The study also shows that it is necessary to create functioning LNG markets that can respond to market dynamics. Either reduction of TOP levels or change of pricing mechanisms to hub prices in LNG contracts would contribute to a functioning LNG markets. While the LNG exporters are shielded from China's uncertainties by the TOP obligation and other commercial arrangement for the time being, such restrictions that fails to reflect market fundamentals are not sustainable. There are ongoing efforts to create spot LNG and gas markets in East Asia (see Shi and Variam (2016) for more details). If the LNG markets are forced to response to China’s low demand in the future by reducing contract restrictions the high cost producers, such as Australia will suffer more (see Shi and Variam (2015) for more details). In this sense, high costs LNG suppliers will 
tend to maintain the current rigorous LNG contract arrangement. It also implied that China should further pursue flexible gas contract arrangements to allow it gas markets to follow economics in the markets, and thus to be able to benefit from low costs of imports. 


\section{References}

Andrews-Speed, P., Yao, L., Zahur, N.b., Rohatgi, A., M.P., H., Regan, T., Linga, P., 2015. International Outlook for Unconventional Gas and Implications for Global Gas Markets Energy Studies Institute, National University of Singapore, Singapore.

Blume, A., 2015. Reform is key to China's future gas demand growth, Gastech News and Resource Centre.

BP, 2015. Energy Outlook 2035. URL: http://www.bp.com.

BP, 2016. Statistical Review of World Energy 2016. British Petroleum, London.

Butler, N., 2015. After the oil price fall, is natural gas next?, Financial Times.

CCR, 2013. Supply-Demand Forecast of China's Natural Gas, China Chemistry Reporter. China National Chemical Information Centre.

CEFC, 2013. CEFC China Energy Focus: Natural Gas 2013. China Energy Fund Committee (CEFC), Hong Kong.

Chen, C., Sinha, S., West, J. C., and Pickup, M. , 2013. China Oilfield Services, in: Barclays (Ed.). Barclays, Hong Kong.

Chen, M., 2014. The Development of Chinese Gas Pricing: Drivers, Challenges and Implications for Demand. OIES, Oxford.

CNPC, 2016a. China's Natural Gas Market Overview, Tokyo.

CNPC, 2016b. Zhong Guo Neng Yuan Zhan Wang 2030 [China Energy Forecast 2030 Release] China.

Diao, H., Wang, Q., Wang, P., Zhao, X., 2014. Zhong Guo Li Yong Hai Wai You Qi Zi Yuan Cheng Guo Ji

Zhan Wang [Oil and Gas Supplement from Overseas: An Overview and Outlook]. Natural Gas Industry 34,

147-152.

Dodge, E., 2016. Impact of Falling Oil Prices on LNG.

EIA, 2015. World Shale Resource Assessments (Last updated: September 24, 2015). Energy Information Agency.

Gastreich, P., Oldfield, S., Peng, Y., Chen, B., Ramsay, G., Li, B., Liu, K., 2013. China Integrated Natural Gas: Accelerated Growth Outlook. UBS Investment Research, Hong Kong.

GIIGNL, 2016. The LNG Industry-GIIGNL Annual Report 2016 Edition. International Groupd of Liquified Natural Gas Importers, France.

Green, F., Stern, N., 2015. China's "new normal": structural change, better growth, and peak emissions. Policy report, Centre for Climate Change Economics and Policy (CCCEP), University of Leeds.

Guo, J., Zhou, J., 2015. Cong Ding Jia Ji Zhi Gai Ge Ru Shou Ti Sheng Tian Ran Qi Xu Qiao [Increasing Natural Gas Demand through Pricing Mechanism Reforms], Shi You Shang Bao [Oil Commercial Paper]. Guo, M., Xu, Y., Chen, Y.D., 2014. Fracking and pollution: can China rescue its environment in time? Environmental science \& technology 48, 891-892.

IEA, 2015a. Medium-Term Gas Market Report 2015.

IEA, 2015b. World Energy Outlook 2015. IEA, Paris.

IEA, 2016. World Energy Outlook 2016.

IEEJ, 2015. Asia/World Energy Outlook 2015. IEEJ.

Krupnick, A., Wang, Z., Wang, Y., 2014. Environmental risks of shale gas development in China. Energy Policy 75, 117-125.

Li, S.-Q., Zhang, B.-S., Tang, X., 2016. Forecasting of China's natural gas production and its policy implications. Petroleum Science 13, 592-603.

Ministry of Finance, 2012. Notice on Subsidy Policy for Shale Gas Development, in: Ministry of Finance of PRC (Ed.), Caijian [2012] 847, Beijing. 
Ministry of Finance, 2015. Notice on Subsidy Policy for Shale Gas Development, in: Finance, M.o. (Ed.), Caijian [2015] 112, Beijing.

Ministry of Finance, 2016. Notice on Increased Subsidy to Shale Gas Development in the 13fh Five-Year-Plan Period, in: Ministry of Finance of PRC (Ed.), Caijian [2016] 31, Beijing.

NDRC, 2014a. Guo Jia Ying Dui Qi Hou Bian Hua Gui Hua (2014-2020) [National Strategy for Climate Change (2014-2020)], in: (NDRC), N.D.a.R.C. (Ed.).

NDRC, 2014b. Notice on Adjusting Prices for Existing Gas Volumes for Non-residential Uses (in Chinese). NDRC, Beijing.

Nexant, 2016. Wrold Gas Model. Nexant, London.

Platts, 2015. China's first private LNG import terminal project in Zhejiang delayed. Platts, Singapore.

Por, Y.L., 2013. China Oil \& Gas: Oil Above Water BNP Paribas, Hong Kong.

Ratner, M., Nelson, G.M., Lawrence, S.V., 2016. China's Natural Gas: Uncertainty for Markets.

Congressional Research Service.

Reig, P., Luo, T., Proctor, J.N., 2014. Global shale gas development: water availability and business risks. World Resources Institute.

Ren, J., Tan, S., Goodsite, M.E., Sovacool, B.K., Dong, L., 2015. Sustainability, shale gas, and energy transition in China: Assessing barriers and prioritizing strategic measures. Energy 84, 551-562.

Rogers, H., 2015. The Impact of Lower Gas and Oil Prices on Global Gas and LNG Markets. OIES, Oxford. Rogers, H.V., Stern, J., 2014. Challenges to JCC pricing in Asian LNG markets. OIES Paper: NG 81.

Ryan, M., 2012. LNG Exports from the US to Asia Seen as Profitable - for a Limited Time.

Shaikh, F., Ji, Q., 2016. Forecasting natural gas demand in China: Logistic modelling analysis. International Journal of Electrical Power \& Energy Systems 77, 25-32.

Shi, F., 2016a. Outlook of China's gas demand/supply, in: Media, A. (Ed.). Argus Media.

Shi, X., 2011. China's Coal Industry Transformation: Performance, Challenges and Prospects, Crawford School of Economics and Government, ANU College of Asia and the Pacific. The Australian National University, Canberra.

Shi, X., 2016b. The Impact of Low Oil Prices on Natural Gas and Implications for the Asia-Pacific. National Bureau of Asian Research, Washington, D.C.

Shi, X., Variam, H.M.P., 2015. China's Gas Market Liberalisation--The impact on China-Australia gas trade, in: Song, L., Garnaut, R., Cai, F., Johnston, L. (Eds.), China's Domestic Transformation in a Global Context. ANU Press, Canberra, pp. 137-174.

Shi, X., Variam, H.M.P., 2016. Gas and LNG trading hubs, hub indexation and destination flexibility in East Asia. Energy Policy 96, 587-596.

State Council, 2014a. Catalogue of Investments Requiring Government Approval (2014) (in Chinese). The State Council, Beijing.

State Council, 2014b. Energy Development Strategy Action Plan (2014-2020) (in Chinese). General Office, State Council PRC, Beijing.

Sun Hui Shan Lei Wang, X., 2013. Development and Future of Natural Gas Industry in China. 中国油气: 英文版, 32-36.

The 18th Central Committee of CPC, 2013. Decision of the Central Committee of the Communist Party of China on Some Major Issues Concerning Comprehensively Deepening the Reform, Beijing.

Tian, L., Wang, Z., Krupnick, A., Liu, X., 2014. Stimulating shale gas development in China: A comparison with the US experience. Energy Policy 75, 109-116.

Trevor, H., Bao, B., 2013. The Geopolitics of Natural Gas: Charting China's Natural Gas Future. Harvard University's Belfer Center,Rice University's Baker Institute Center of Energy Studies.

Wang, C., Wang, F., Du, H., Zhang, X., 2014. Is China really ready for shale gas revolution-Re-evaluating shale gas challenges. Environmental Science \& Policy 39, 49-55. 
Wang, J., Feng, L., Zhao, L., Snowden, S., 2013a. China's natural gas: Resources production and its impacts, . Energy Policy 55, 690-698.

Wang, J., Feng, L., Zhao, L., Snowden, S., 2013b. China's natural gas: Resources, production and its impacts. Energy Policy 55, 690-698.

Wang, J., Mohr, S., Feng, L., Liu, H., Tverberg, G.E., 2016. Analysis of resource potential for China's unconventional gas and forecast for its long-term production growth. Energy Policy 88, 389-389.

Wang, T., Lin, B., 2012. Forecasting natural gas supply in China: Production peak and import trends, . Energy Policy 49, 225-233.

Wang, T., Lin, B., 2014. Impacts of unconventional gas development on China's natural gas production and import. . Renewable \& Sustainable Energy Reviews 39, 546-554.

Yang, H., Flower, R.J., Thompson, J.R., 2013. Shale-gas plans threaten China's water resources. Science 340, 1288-1288.

Zeng, B., Li, C., 2016. Forecasting the natural gas demand in China using a self-adapting intelligent grey model. Energy 112, 810-825.

Zhang, K., 2014. Natural gas supply-demand situation and prospect in China. Natural Gas Industry B 1, 103-112.

Zhang, Q., Li, Z., Wang, G., Li, H., Mälardalens, h., Framtidens, e., Akademin för ekonomi, s.o.t., 2015. Study on the impacts of natural gas supply cost on gas flow and infrastructure deployment in China.

Applied Energy.

Zhang, W., Yang, J., 2015. Forecasting natural gas consumption in China by Bayesian Model Averaging. Energy Reports 1, 216-220.

Zhu, Q., Lu, Q.-Y., Zhou, X.-Y., Lai, K.K., 2014. A Driving Force Analysis and Forecast for Gas Consumption Demand in China. Mathematical Problems in Engineering 2014, 1-11. 